\title{
Lamina spreader technique improves debridement of loose bone and cement in total knee arthroplasty
}

Sinan E. Ozgur, $\mathrm{MD}^{1}$, Ali Oliashirazi, $\mathrm{MD}^{1}$, Grant S. Buchanan, $\mathrm{MD}^{1}$, Franklin Shuler, MD, $\mathrm{PhD}^{1}$

\section{Author Affiliations:}

1. Department of Orthopaedics, Marshall University Joan C. Edwards School of Medicine, Huntington, West Virginia

The authors have no financial disclosures to declare and no conflicts of interest to report.

Corresponding Author

Sinan E. Ozgur, MD

Email: sinan.e.ozgur@gmail.com 


\section{Abstract}

Loose bone and cement can promote polyethylene wear that may lead to failure in total knee arthroplasty. The authors propose a technique to enhance the debridement of loose bodies by distracting the cemented components with a lamina spreader following standard debridement with pulsatile lavage. Cement and bone/soft tissue debris was recovered from 51 consecutive primary total knee arthroplasty patients. This technique facilitated the removal of hidden debris in $80 \%$ of patients (41/51). On average, 2.6 fragments measuring $158 \mathrm{~mm}^{3}$ were removed per patient. The authors advocate that distraction with a lamina spreader be used to reduce potential sources of wear.

\section{Key Words}

Total knee replacement, total knee arthroplasty, third body wear, debris

\section{Introduction}

Total knee arthroplasty (TKA) has proven to be an invaluable treatment for the debilitating pain and dysfunction associated with osteoarthritis. The overall survivorship of TKA has been quoted by numerous studies to be from $91-98 \%$ after $15-23$ years. ${ }^{1-5}$ The widespread performance of TKA is projected to continue, with demand to increase $673 \%$ by 2030 ; consequently, the rate of revision is expected to increase by $601 \%$ in that same time. ${ }^{6}$ Common reasons for TKA revision include infection (18.4\%), aseptic loosening (23.1\%), instability (17.7\%), and polyethylene wear $(18.1 \%)^{7}$

Despite major advances in mechanical engineering and materials science over the last few decades, mechanical wear still plays a critical role in the failure of TKA. It occurs via mechanisms such as abrasion, adhesion, and fatigue. Third body wear is a form of abrasive wear that occurs when loose bodies such as polymethymethacrylate (PMMA), bone, metal, or polyethylene grind between articulating surfaces and damage the implant, primarily affecting the polyethylene insert. ${ }^{8}$ It has been shown that the age of the prosthesis correlates with the amount of particulate debris. Furthermore, the amount of debris adjacent to the implant correlates with the extent of surface damage. ${ }^{9}$ Que et al. demonstrated with electron microscopy that loose PMMA and bone debris caused significant surface damage to femoral articulating surfaces. ${ }^{10}$ With roughened surfaces, third body abrasive wear is increased, perpetuating polyethylene wear debris, forming a cycle which results in the failure of the prosthesis. The buildup of debris not

only damages the implant, but causes bone resorption via the recruitment of macrophages. ${ }^{11,12}$ For these reasons, prevention of third body wear should be a high priority. In this article, the authors present a technique involving the distraction of cemented components using a lamina spreader; this technique successfully facilitates the removal of third body debris that would be missed after standard debridement with pulsatile irrigation.

\section{Surgical Technique}

This project was approved by an institutional review board. A total of 51 consecutive patients with severe arthritis of the knee underwent primary TKA using a posterior stabilized system 
(Depuy, Warsaw IN) by a single total joint surgeon (AO). After all components were cemented (Depuy, Warsaw IN), with the trial polyethylene removed, a standard debridement was performed where the knee was hyperflexed and all visible debris was removed from the anterior, posterior, medial, and lateral surfaces and the joint was flushed with three liters of pulsatile irrigation (Pulsavac, Zimmer Inc., Warsaw IN). Following this standard debridement, the posterior compartment of the knee was exposed by flexing the knee to 90 degrees and having the assistant pull up on the distal thigh against gravity (Figure 1). A lamina spreader was introduced to the non-articulating, posterior aspect of the tibial and femoral components, and gentle distraction was applied to improve the inspection of the posterior compartment (Figure 1). An additional debridement was performed and any remaining cement and bone/soft tissue fragments were removed and measured. After placement of the final polyethylene insert and final knee stability testing, the knee underwent standard closure.

Figure 1: Intra-operative photograph demonstrating the distraction technique. A carefully placed lamina spreader distracts the femoral and tibial components after cementation in a flexed knee. Improved posterior visualization is achieved benefiting debridement.

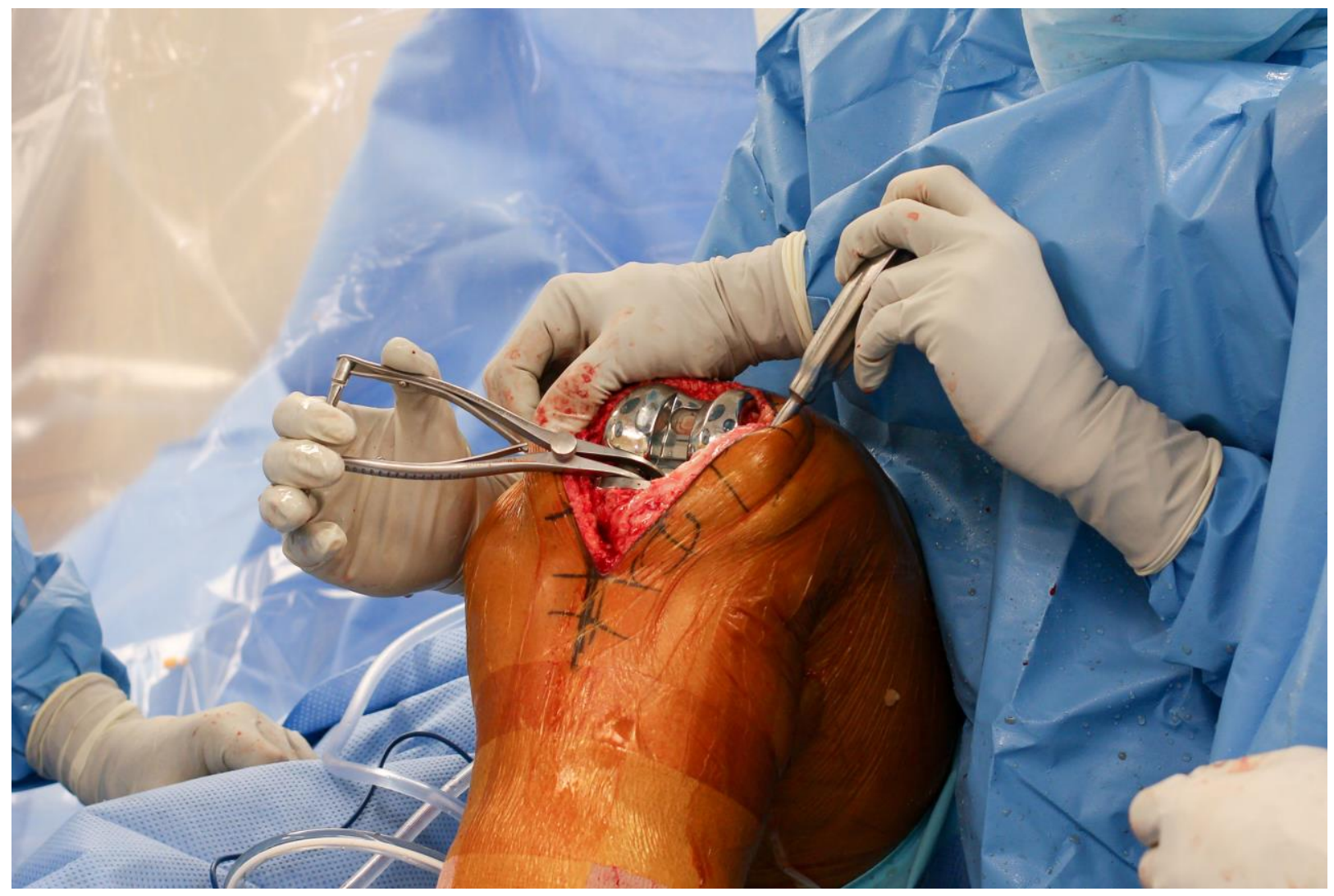




\section{Results}

Distraction with a lamina spreader facilitated the removal of hidden cement or bone/soft tissue fragments in $80 \%$ of patients (41/51); this debris would have been missed after standard debridement with pulsatile irrigation alone. Table 1 shows the quantity and size of the loose fragments. Overall, 35 patients $(69 \%)$ had cement fragments removed, and 24 patients $(47 \%) \mathrm{had}$ bone/soft tissue fragments removed. It is worth noting that for one patient, distraction allowed visualization of an actively bleeding vessel which was then cauterized.

Table 1. Quantity and size of loose bodies found using the distraction technique.

\begin{tabular}{|c|c|c|c|c|}
\hline Particle & $\#$ & $\begin{array}{c}\text { Average volume } \\
\left(\mathrm{mm}^{3}\right)\end{array}$ & Range $\left(\mathrm{mm}^{3}\right)$ & $\begin{array}{c}\text { Average \# } \\
\text { removed }\end{array}$ \\
\hline Cement & 85 & 138 & $5-926$ & 1.7 \\
\hline Soft Tissue or Bone & 48 & 194 & $2-1913$ & 0.9 \\
\hline Total & 133 & 158 & $2-1913$ & 2.6 \\
\hline
\end{tabular}

\section{Discussion}

Loose bone and cement fragments can have a detrimental effect on polyethylene wear. Although it is now less common than previously reported, polyethylene wear still accounts for $7-18 \%$ of TKA failure. ${ }^{7,13-15}$ Reducing third body debris is critical to the prevention of wear. The technique presented here is noteworthy in that it facilitated the removal of hidden loose bodies in $80 \%$ of patients. The discovery of cement fragments in $69 \%$ of patients is also substantial, as research has shown that cement debris leads to a significantly higher wear rate than bone debris. ${ }^{16}$

Standard surgical technique for TKA emphasizes the removal of all visible bone and cement debris after the insertion of components. Despite a surgeon's best efforts to remove debris, studies have demonstrated a high potential for retained loose bodies after pulsatile irrigation during TKA. ${ }^{17-19}$ Helmers et al. found an average of $537 \mathrm{mg} / \mathrm{L}$ of debris, $79 \%$ of which was bone, after irrigating with 3 liters of solution prior to implantation. ${ }^{17}$ Following implantation, an average of $217 \mathrm{mg} / \mathrm{L}, 52 \mathrm{mg} / \mathrm{L}$, and $49 \mathrm{mg} / \mathrm{L}$ of debris was found after pulsatile irrigation with a fourth, fifth, and sixth liter of fluid respectively; $53 \%$ of particles were bone and $47 \%$ were PMMA and soluble organics. ${ }^{17}$ De Baets et al. found that an average of $134.9 \mathrm{mg}$ of debris was retrieved prior to closure of TKA; debris recovered consisted of bone $(56.5 \%)$, cement $(42.0 \%)$, and metal (1.5\%). ${ }^{18}$ A study by Niki et al. identified 6-20 debris particles $>1 \mathrm{~mm}$ in size after one liter of pulsatile irrigation. ${ }^{19}$ The results of the present study are consistent with previous literature. Three liters of pulsatile irrigation was performed, yet on average, 2.6 fragments were removed following distraction with a lamina spreader. This technique is limited in that it only aids debridement of grossly visible fragments, despite third body wear being known to occur with microscopic particles. Potential complications that could occur with this technique might include scratching the articular surface of the components, if care is not taken during placement; also, excessive distraction could cause damage to the posterior capsule, affecting gap balancing and stability. 


\section{Conclusion}

The authors demonstrate that a simple distraction technique can facilitate the removal of retained cement and bone/soft tissue debris in $80 \%$ of patients. In 51 patients, an average of 2.6 hidden fragments with a size of $158 \mathrm{~mm}^{3}$ (larger than a standard pencil eraser) was removed during distraction with a lamina spreader. The authors advocate that distraction with a lamina spreader be used during TKA as a means to reduce potential sources of third body wear. 


\section{References}

1. Pavone V, Boettner F, Fickert S, Sculco TP. Total condylar knee arthroplasty: a long-term followup. Clinical orthopaedics and related research. 2001(388):18-25.

2. Ritter MA, Meneghini RM. Twenty-year survivorship of cementless anatomic graduated component total knee arthroplasty. The Journal of arthroplasty. 2010;25(4):507-13.

3. Gill GS, Joshi AB. Long-term results of Kinematic Condylar knee replacement. An analysis of 404 knees. The Journal of bone and joint surgery British volume. 2001;83(3):355-8.

4. Buechel FF, Sr., Buechel FF, Jr., Pappas MJ, D'Alessio J. Twenty-year evaluation of meniscal bearing and rotating platform knee replacements. Clinical orthopaedics and related research. 2001(388):41-50.

5. Dixon MC, Brown RR, Parsch D, Scott RD. Modular fixed-bearing total knee arthroplasty with retention of the posterior cruciate ligament. A study of patients followed for a minimum of fifteen years. The Journal of bone and joint surgery American volume. 2005;87(3):598-603.

6. Kurtz S, Ong K, Lau E, Mowat F, Halpern M. Projections of primary and revision hip and knee arthroplasty in the United States from 2005 to 2030. The Journal of bone and joint surgery American volume. 2007;89(4):780-5.

7. Dalury DF, Pomeroy DL, Gorab RS, Adams MJ. Why are total knee arthroplasties being revised? The Journal of arthroplasty. 2013;28(8 Suppl):120-1.

8. Schmalzried TP, Callaghan JJ. Wear in total hip and knee replacements. The Journal of bone and joint surgery American volume. 1999;81(1):115-36.

9. Hirakawa K, Bauer TW, Yamaguchi M, Stulberg BN, Wilde AH. Relationship between wear debris particles and polyethylene surface damage in primary total knee arthroplasty. J Arthroplasty. 1999;14(2):165-71.

10. Que L, Topoleski LD. Third-body wear of cobalt-chromium-molybdenum implant alloys initiated by bone and poly(methyl methacrylate) particles. Journal of biomedical materials research. 2000;50(3):322-30.

11. Davidson JA, Poggie RA, Mishra AK. Abrasive wear of ceramic, metal, and UHMWPE bearing surfaces from third-body bone, PMMA bone cement, and titanium debris. Bio-medical materials and engineering. 1994;4(3):213-29.

12. Horowitz SM, Doty SB, Lane JM, Burstein AH. Studies of the mechanism by which the mechanical failure of polymethylmethacrylate leads to bone resorption. J Bone Joint Surg Am. 1993;75(6):802-13.

13. Thiele K, Perka C, Matziolis G, Mayr HO, Sostheim M, Hube R. Current failure mechanisms after knee arthroplasty have changed: polyethylene wear is less common in revision surgery. The Journal of bone and joint surgery American volume. 2015;97(9):715-20.

14. Schroer WC, Berend KR, Lombardi AV, Barnes CL, Bolognesi MP, Berend ME, et al. Why are total knees failing today? Etiology of total knee revision in 2010 and 2011. The Journal of arthroplasty. 2013;28(8 Suppl):116-9.

15. Lombardi AV, Jr., Berend KR, Adams JB. Why knee replacements fail in 2013: patient, surgeon, or implant? The bone \& joint journal. 2014;96-b(11 Supple A):101-4.

16. Schroeder C, Grupp TM, Fritz B, Schilling C, Chevalier Y, Utzschneider S, et al. The influence of thirdbody particles on wear rate in unicondylar knee arthroplasty: a wear simulator study with bone and cement debris. Journal of materials science Materials in medicine. 2013;24(5):1319-25.

17. Helmers S, Sharkey PF, McGuigan FX. Efficacy of irrigation for removal of particulate debris after cemented total knee arthroplasty. J Arthroplasty. 1999;14(5):549-52.

18. De Baets T, Waelput W, Bellemans J. Analysis of third body particles generated during total knee arthroplasty: is metal debris an issue? Knee. 2008;15(2):95-7.

19. Niki Y, Matsumoto H, Otani T, Tomatsu T, Toyama Y. How much sterile saline should be used for efficient lavage during total knee arthroplasty? Effects of pulse lavage irrigation on removal of bone and cement debris. J Arthroplasty. 2007;22(1):95-9. 